\title{
Creating e-learning Content Storyboard Based on Instructional Design Principles
}

\section{Sunil Kumar B*}

Sai Vidya Vikas Shikshanasamithi, India

\begin{abstract}
Creating e-learning Content Storyboard Based on Instructional Design Principles provides learners with the opportunity to enhance their learning experience through greater interaction with course material and the ability to control their learning environment. A fast dissemination of knowledge is a critical element to organizational success. It also gives recommendations for future studies that could be conducted based on this research.
\end{abstract}

Keywords: Instructional Design; Testing; SME; Programming language; Organization

\section{Introduction}

This chapter contains the overview of the study that has been conducted. It outlines the problem statement and the objectives of the research. It also gives a brief introduction on the research methods that was conducted. E-learning can be defined as leveraging on the power of information and communications technology to drive learning online as part of the traditional instructor-led learning, distance education or professional training. It provides learners with the opportunity to enhance their learning experience through greater interaction with course material and the ability to control their learning environment. With e-learning, learners are not bounded by the time constraints and they can learn at their desired pace. Over the past few years, many corporations have been introducing e-learning or at least formed an e-learning strategy in trying to embed a continuous learning culture within their people to cope with the continual change and remain competitive in the business world. In fact, a vast majority of Fortune 500 companies has already implemented some form of e-learning to deliver continuous professional development and training to their employees. For example, IBM's Chief Learning Officer, Ted Hoff, has been quoted for saying that IBM conducts $48 \%$ of its employee training via the electronic means as they find it as the most efficient way to train more than 320,000 employees scattered over 76 countries. On top that IBM was able to trim the training cost by USD400 million a year. The employees have to process more information in a shorter amount of time as new products and services are emerging with accelerating speed. This also makes the lifespan of the products short hence product information and training becomes obsolete quickly. Product knowledge and skills then has to be delivered more rapidly and efficiently whenever and wherever needed. A fast dissemination of knowledge is a critical element to organizational success. E-learning provides the ease of deploying training on demand since course materials can be accessed via the Internet. It is because of this trend, predicts the E-Learning industry will grow 16.7 percent annually worldwide from 2003 through 2008, and by that time, the industry will be generating an estimated USD $\$ 619.4$ million in revenue. As the main hurdles to e-learning, such as lack of interactivity, content availability, technology standards, and bandwidth, are currently being addressed, the technological barriers that once hindered the successful deployment of e-learning are beginning to diminish. Especially with the continued adoption of broadband by the Government, it should facilitate higher use rates of media-rich e-learning products. This makes e-learning is one of the fastest growing and most promising markets in the education industry. E-learning course materials are usually found in the form of a courseware. A courseware is computer-based educational multimedia software. It provides interactive learning sessions that may contain text, computer graphics, images, animation, sound and motion video. These media elements and interactivity coupled with a well structured content helps learner to gain better retention of the subject matter. The interactive course content of an e-learning courseware compensates for the absence of a trainer. A courseware can provide a high level of simulation that can be adjusted according to the learners' proficiency. Learners can access the courseware anytime, learn at their own pace and review the course material as often as needed. When a learner has more control over their learning process, they are able to better understand the material, leading to a $60 \%$ faster learning curve compared to the traditional instructor-led training. Coursewares are commercially available in the open market as an off-the-shelf product. However, most corporations prefer to develop custom courseware for certain subject areas. For example, it is almost impossible to find third-party courseware that relates to the corporations' unique culture, working methodology, or values. A courseware of these natures usually needs to be custom built. According to the International Data Corporation (IDC), in 2003, large corporations spending on e-learning rose by $22 \%$ as compared to the previous year. IDC also predicts that the e-learning spending trend will rise by an average of $27 \%$ until the year 2008 . This shows demand for custom content is rising quickly than demand for off-the-shelf content products. In particular, large corporations place high value on customized high-quality content as they see it as a key differentiator against their competition. The core ingredient to any courseware is the content. Content needs to be structured in a manner that can utilize the media elements to enhance learning experience. A well developed content design would guarantee the effectiveness of the learning outcome from the multimedia courseware. Therefore, it is essential that some form of pedagogical element exists in the content design to ensure that the content is relevant and able to achieve its teaching objective. In developing content for custom courseware, the organization's Subject Matter Experts (SME) need to gather all materials related to the subject,

*Corresponding author: Sunil Kumar B, Sai Vidya Vikas Shikshanasamithi, India, E-mail: sunilfrench@gmail.com

Received April 09, 2013; Accepted July 19, 2013; Published July 26, 2013

Citation: Sunil Kumar B (2013) Creating e-learning Content Storyboard Based on Instructional Design Principles. J Mass Communicat Journalism 3: 156. doi:10.4172/2165-7912.1000156

Copyright: () 2013 Sunil Kumar B. This is an open-access article distributed under the terms of the Creative Commons Attribution License, which permits unrestricted use, distribution, and reproduction in any medium, provided the original author and source are credited. 
decide which content is relevant and organize it in a coherent form. These contents would then need to be repurposed into an instructional form before it can be ready for courseware production. This would be the task of an Instructional Designer (ID) and storyboarding is the popular method for formatting contents into an instructional mode.

A storyboard is the documentation for interactive multimedia production. It contains instructions for programming, an audio script, and a detailed description of the visual elements such as text, video, graphics, and animation. The storyboard becomes the key design document that the entire production team uses as a base for developing the interactive program.

This thesis was conducted to explore the possibility of creating an application to assist the SME to construct e-learning content storyboards based on an instructional design principle and to determine whether such an application could be an effective means in assisting the SME to develop content storyboard that abides by such instructional design principles.

\section{System design}

This chapter uses the finding from Chapter 3 in order to draft the application's requirement and design.

\section{System implementation and testing}

This chapter describes the implementation strategy used and the testing procedure that was conducted on the application before it was release for appraisal by the sample group.

\section{Survey findings of application reviews}

This chapter presents the findings of the research study and summarises the findings.

\section{Statement of problem}

The following list of problem statements outlines the issues faced by IDs and SMEs involved in e-learning content development.

Lack of learning theories by the SMEs: The challenge here lies with the fact that most SME are groomed by the industry and were not exposed to any learning theories. Even though some SME do conduct in-house training, their approach is mainly based on training guidelines and standard materials that are provided to them by the corporation. Even if the SME have the experience of constructing training content, their content might not be based on a solid framework of instructional design principles. Thus the content will not be able to help the learning process hence, effective knowledge transfer and retention cannot take place. Content that is not based on sound principles are likely to fail to achieve its intended learning outcome. The deficient knowledge of learning theories makes it difficult for SME to construct viable instructional content.

SMEs lack constant guidance throughout content development process: Developing content for e-learning is no different from traditional teaching content in the sense that it must be based on a solid foundation. Furthermore, e-learning provide options for SME to include multimedia elements and interactivity that has never been possible with traditional ones. SME are spoilt with choices to enhance their content. However, these ability and appealing options often results in haphazard content design that is not instructionally sound and did not match the learning objective. SME needs to be reminded and constantly guided throughout the content development process to ensure they do not go overboard with content design.
Heavy burden on IDs during initial stage of content development: The lack of pedagogical perspective during content design tends to make the SME handover the daunting tasks of designing content to ID. A typical scenario would be that the SME would simply pass a stack of unstructured training materials and expects the ID to go through it before engaging in a discussion with the SME on how to process the raw content. The ID is left with a heavy burden as they have to grasp the essence the training materials before they could actually decide on how to repurpose it into an instructional form. After which, the ID would then have to convert the content design into a storyboard format. This would also mean the turnaround time for the content storyboarding would be prolonged as digesting training material of an unfamiliar subject could take up days or even weeks.

Slow turnaround time due to time constraint: Since the ID and SME are two different groups of people being pulled together to work on a content project, it would be very difficult to set a common schedule for these two parties to congregate and collaborate on their content development effort. Should there be more than one SME required for a particular content project, scheduling would be an even greater effort especially if the two SME comes from a different department, or worst, a different organisation. This is another contributing factor to the slow cycle of generating content storyboard.

High development cost due to engagement of external ID: Most organizations do not employ in-house ID. IDs are usually external consultants that are being paid premiums to render their services. The long duration of time spent by the ID would mean an escalating cost to the organisation. The heavy cost in turn would force the organisation to cut back on developing further e-learning content that could have benefited the employees and growth of the company. Even worst would be organisation trying to cut corners by disregarding the importance of proper content design by eliminating the role of an ID altogether. Therefore, reducing the task of the ID by removing certain job function could help cut consultation time and reduce the cost of developing an e-learning content.

The task of drafting the content storyboard should be the responsibility of the SME. If SME are able to construct the content storyboard independently in the proper and correct manner, it could help speed up the content development lifecycle. The dependency on the ID would then be reduced to merely editing and monitoring storyboards development instead of composing one. This could also be a cost cutting measure for the organisation to reduce cost by lowering the hours needed to engage external ID.

Lack of suitable application that would expedite development process: In order to make it easier for the SME to generate an e-learning content storyboard, there need to be an application to assist them in this conquest. However, there are no known applications available for creating e-learning content storyboard that caters for SME as their target user. The points stated above gives the motivation for creating such an application to overcome the problem of content development. This particular application should address the problems as stated above by:

1. Providing a guideline of instructional design framework for SME to follow during content storyboarding development.

2. Providing a platform to promote the collaboration between SME and ID. It should even support the scenario where multiple SME and ID from different department or organisation are involved in a particular content development effort. 


\section{Literature Review}

This chapter investigates existing work, research and publication that have been conducted with regards to instructional design. The sources for the literature are collected from academic research papers, published journals, product white papers and some online references.

While academic literature or journals on instructional design per se are in abundance, literature with regards to instructional design in the context of e-learning is very difficult to come by. However, the lack of academic materials has been compensated by other forms of literature that also provided great information to this thesis.

Literature reviews provide great insights into the topic being studied from the experts themselves. They act as a stepping stone to this thesis as they provide concrete evidence to findings and hypothesis of previous research that are similar or related to this one. Their finding can therefore be used and deemed as true. The findings and recommendations presented by the authors could also act as a guide or give clues as to what is required in forming the application requirements for the thesis's application.

\section{What is instructional design?}

There are many interpretations to the term 'instructional design'. Sometimes an instructional designer are often called curriculum developer, learning specialist, or even instructional technologist. Now, especially with introduction of the World Wide Web, the term instructional design is sometimes being used to refer to computerhuman interface design or visual interface design with regards to navigational instructions. Therefore, it is very important for this thesis to identify which definition to use in order to avoid confusion and misinterpretation of the term. Instructional design as

"the systematic process of translating principles of learning and instruction into plans for instructional materials and activities."

According instructional design is the procedure of planning the instruction in a manner that induces the learner to actively learn the materials using cognitive strategy. Gros claims that instructional design is the process of providing a link between learning theories or how people learn, and the practice of building instructional systems as arrangement of resources and procedures to promote learning.

From the definitions pointed above, a list of what is not instructional design in the context of this thesis can be deduced as:

- Instructions of using visual elements such as buttons, text field, etc.

- The design of multimedia screens navigational flow.

- The design of multimedia navigation elements such as pull down menus, hyperlinks, etc.

In short, anything with regards to creative multimedia presentation and organization is not considered as part of instructional design. Instructional design in this thesis shall only refer to following context:

- Design of instructional content to stimulate learning.

- Content repurposing to vet out unnecessary information.

- Logical arrangements of content in a manner that induces learning.

\section{A brief history of instructional design}

The history is always a good place to start in trying to determine the future. In trying to understand the shape of instructional design to come, it is therefore important to look into the past and study how the subject was conceived.

In 2004, Leigh wrote an article on the brief history of instructional design for the Performance improvement global network; a chartered chapter of the international society for performance improvement. $\mathrm{He}$ indicated that the study of Instructional Design has been a long time in the making since the era of Aristotle, Plato and Socrates who observed the cognitive basis of learning and memory. The study was then expanded further as a formal discipline in the turn of the $20^{\text {th }}$ century by the works of John Dewey who promoted the notion that learning happens best when it is done practically rather than through a routine or repetitious memorization process. This notion opened the door to the behaviourist approach of educational psychology in the 1920's where the original stimulus-response (S-R) model of behavioural psychology was introduced by Thorndike through his theory of connectionism. Twenty years later Hull expended the idea in his motivational model of behavior which focuses on the learner's wants, attention and activities. By then the World War II was already in the becoming and need to train hundreds of thousand of military personnel arise. Military researchers resorted to a work by Ralph Tyler which indicated that learning objective should be written in terms of desired learner behaviors. They created standardized methods of delivering instructions via training films and other mediated materials. The method proved successful when victory was achieved by the allied forces. The victory sets the motion of heavy investment in the research and development of training methods by the United States government. The economic boom that followed suit saw further government allocation in the research of learning, cognition and instruction.

Benjamin Bloom was amongst those who has benefited from this government funding. In 1956 he came up with taxonomy of intellectual behaviors which provided a guideline for instructors to disseminate knowledge by writing instructional content in an effective manner. Bloom was a firm supporter of a mastery approach to learning. His instructional techniques varied both instruction and time according to learner's requirement and offered instructional developers a way to match subject matter and instructional methods. However, Bloom's taxonomy was unsuitable in large organization because it does not address the performance of individuals in relation to resources and processes.

Research from Bloom's studies sparked Robert Gagné to publish a book entitled "Military Training and Principles of Learning" in 1962 which complements Bloom's six cognitive domains of learning. Gagné points out the different levels of learning that exists within an establishment. Gagné is well known as a behaviourist, and his focus is on the outcomes-or behaviours-that result from training.

Later in 1965 Gagné published another book entitled “The Conditions of Learning" which identified the mental conditions for learning. They were based on the information processing model of the mental events that occur when adults are presented with various stimuli. It included nine instructional events that detail the conditions necessary for learning to occur. Until today these nine events are still being used as a basis for most instructional designer in writing instructional content.

The late 1970's and early 1980's saw a surge in instructional design models. One of the attributes that contributed to the growth was the introduction of formal education and training department in both private and public organizations. By this time, market competition 
has become rapid and most organizations recognized the urgency to develop appropriate methods to train internal employees as business face stiff competition.

The dawn of new media such as the Internet and hypermedia has spawned a new approach to learning and instruction called the constructivist approach. It holds that learners construct their understanding of reality from interpretations of their experiences. Theorists such as Thomas Duffy and Seymour Papert suggest that constructivism provides a model whereby socio-cultural and cognitive issues regarding the design of learning environments can be supported by computer tools. This theory has been applied in many computer technologies such as the online help system as well as the LOGO programming language.

Undoubtedly the study of education theories and principles will continue to grow and progress as the society embarks on new methods of learning or when the technology supporting the learning evolves. However, it is important to realise that there are no single best methods when it comes to education theories. The next section shall discuss the most commonly used learning principles and select the most appropriate one to be used in the pilot implementation of the application.

\section{Research Objectives}

The objectives of this research are as follows;

1. To build an application to create an e-learning content storyboard based on a sound instructional design principle.

2. To determine if the application could help SME to easily generate content storyboard for their subject based on proven Instructional Design Principle.

3. To determine if the application could help IDs to easily monitor or supervise the SME throughout content storyboard creation process.

4. To determine if the application could help reduce the turnaround time to generate a content storyboard.

5. To verify that the storyboard generated by the sample group using the application abides by the Instructional Design Principle adopted by it.

If the research finds that the application proves to be helpful in helping SME to repurpose their content into a teaching and learning form, then the local e-learning industry would benefit as they are able to generate learning content at a greater pace and at a reduced cost. A fast turnaround time would also mean an organisation could deploy their e-learning content on-line faster. As on-line training costs are far economical as compared to an instructor-led training, this would mean the organisation stand to save a huge amount of money in terms of training budget from a faster deployment of the training content.

\section{Research Questions}

The research aims to answer the following questions:

1. Would the SME be able to use the application to generate content storyboards?

2. Will content storyboard produced abides by the chosen learning principles?

3. Will the ID find it easy to invigilate the SME through this application?

4. Will it improve the process of creating e-learning content storyboard?

\section{Research Methodology}

The application must be built before it could be used by the sample group to test its usability and effectiveness. Due to the limitation of time and financial constraints, the requirements definition or application functional scope shall be derived from interviews with principle e-learning consultants from local companies whose core business is in the e-learning service industry. The application functional scope will be based on the content storyboarding process practiced in that company. The principal consultants shall conduct the user acceptance test on the application upon it being built before the application could be used by the sample test group. The application to be developed will be a WebBased Application as it provides end-users or SME greater access to the application without the geographical boundary. It will be an opensource application, based on the PHP-MySQL programming language to provide room application enhancements in the future. The application will provided users with a step-by-step form-based template for content insertion. Content will be inserted based on a selected Instructional Design principle. Instructions will be added to guide users along the way. A feature to convert the storyboard into a PDF format will also be included. The application will automatically format the content to the appropriate storyboard layout ready for printing. The sample test group will consists of SMEs, multimedia programmer, graphic designers, ID and others who are involved in content development. Each respondent will use the application according to their role in the content storyboard production, for example the SME shall be composing the content, while the ID will be monitoring and make necessary adjustments. SME user group will be from the corporate sectors as they do not posses any formal training in pedagogical and learning theories. This is important as we are trying to determine if the absence of fundamental knowledge will have an adverse effect on the outcome of the content to be developed. Target number of SME shall be in the range of 10 to 15 people. ID user group however must consist of qualified people with a strong knowledge on instructional design principle and processes. The ID will be responsible for monitoring the SME development progress therefore it is crucial for them to be equipped with the necessary skill-sets for the task. Target number of ID will be less than the SME as one ID could monitor multiple SME. Target number of ID shall be in the range of 5 people. The study shall be of a quantitative nature where questionnaires shall be the instrument for data collection. Data collection will be done after the sample group have experienced using the application for a certain period of time. SPSS will be used to analyse the data collected.

\section{Significance of Study}

This study is deemed significant because if such an application could be built and prove to be effective, it would not only benefit the e-learning industry but the knowledge based industries as well. Companies or organisation would then be able to empower their SMEs repurpose their existing knowledge base into a teaching and learning form and disseminated that knowledge to other employees. By empowering the SMEs, development time and cost of content production could be reduced significantly. Reduction in development cost would spur organisation to repurpose more of their existing training materials or knowledge base into e-learning format thus giving employees greater access to the knowledge based content. This would also encourage organisations that has not implement e-learning to embark on it as the savings in terms of training cost has already been enjoyed by most huge multinationals. Lower cost of content development would enable organisations to enjoy greater savings during pre and post e-learning deployment. The ability to speed up learning content generation would definitely increase the organisation's competitive advantage as their 
Citation: Sunil Kumar B (2013) Creating e-learning Content Storyboard Based on Instructional Design Principles. J Mass Communicat Journalism 3: 156. doi:10.4172/2165-7912.1000156

Page 5 of 5

employees will always be equipped with the latest knowledge and hence drive the organisation forward at a greater pace.

\section{Scope of Study}

The scope of this study is restricted to the usage of an application to generate e-learning content storyboards. This thesis does not intent to address other issues pertaining to courseware development such as the issue of courseware production once the storyboard is ready. Since the SME are from the corporate sector, the target audience for the content to be generated will be working adults in the same sector. The contents to be generated are thus catered for adult learners and thus will be based on an adult learning principle. Based on the targeted user group, the learning principle that has been identified for exercise will be Gagne's Nine Learning Events (Gagne, 1992). No other learning principles shall be used or made to compare with Gagne's learning principle. The study will not consider demographics such as gender, race, domicile and socioeconomics status of the SME. These variables include status of SME in the organisation as their role and job scope within the corporation is not considered a factor that could affect the outcome of the content storyboard. Also, because the study is focused on a corporate environment, its findings cannot be generalised to all organisations in other sectors wishing to create e-learning content storyboards using the application. In addition, the data to the study cuts across the boundary of subject matter. This study offers an overall indication of the effectiveness of using an application for generating content storyboard and no comparison shall be made between the outcomes of content storyboards of differing discipline. It also does not intend to prove or disprove any learning theory's effectiveness.

\section{Thesis Organization}

In order to present the fact of work conducted in an orderly fashion, this thesis' chapters will be organised in the following manner:

\section{Research methodology}

This chapter details the research methodology and approach conducted used in this study.

\section{Conclusion}

This chapter analyses the summary of the research findings and discusses its implications towards the thesis' objectives. It also gives recommendations for future studies that could be conducted based on this research. 